First Peoples Child \& Family Review

A Journal on Innovation and Best Practices in Aboriginal Child Welfare Administration,

Research, Policy \& Practice

\title{
Here be dragons! Reconciling Indigenous and Western knowledge to improve Aboriginal child welfare
}

\section{Jean LaFrance and Betty Bastien}

Volume 3, Number 1, 2007

URI: https://id.erudit.org/iderudit/1069530ar

DOI: https://doi.org/10.7202/1069530ar

See table of contents

Publisher(s)

First Nations Child and Family Caring Society of Canada

ISSN

1708-489X (print)

2293-6610 (digital)

Explore this journal

Cite this article

LaFrance, J. \& Bastien, B. (2007). Here be dragons! Reconciling Indigenous and Western knowledge to improve Aboriginal child welfare. First Peoples Child \& Family Review, 3(1), 105-126. https://doi.org/10.7202/1069530ar
Article abstract

The authors discuss the factors regarding the reconciliation movement in reconciling Indigenous and Western Knowledge to improve child welfare practice with respect to Aboriginal peoples. In particular, a current initiative undertaken in collaboration with various First Nation communities in Alberta involved with the "Making Our Hearts Sing" Initiative is highlighted. This initiative aimed to build on collaboration among child welfare stakeholders and Aboriginal communities to examine issues relating to child welfare that would be more in keeping with traditional Aboriginal worldviews that could, at the same time, contribute to reconciliation, healing and increased community capacity.
This document is protected by copyright law. Use of the services of Erudit (including reproduction) is subject to its terms and conditions, which can be viewed online.

https://apropos.erudit.org/en/users/policy-on-use/ 
First Peoples Child \& Family Review

A Journal on Innovation and Best Practices in Aboriginal Child Welfare

Administration, Research, Policy \& Practice

\title{
Volume 3, Number 1, 2007, pp. 105-126
}

\section{Here be dragons! Reconciling Indigenous and Western knowledge to improve Aboriginal child welfare}

\author{
Jean Lafrance and Betty Bastien
}

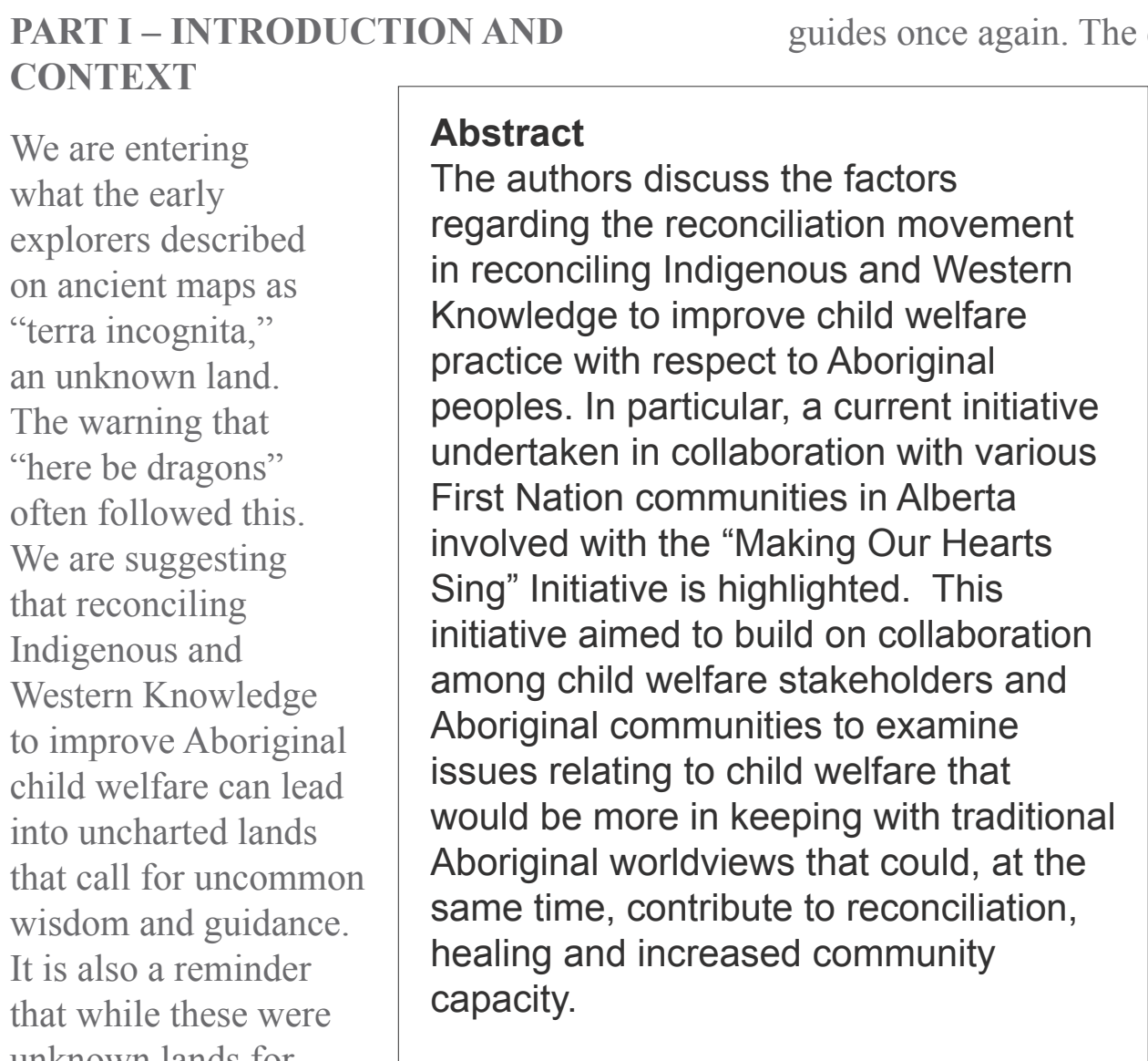

uestion then becomes whether those who are or have been part of oppressive systems that had such a negative impact upon Aboriginal people can play a legitimate role in addressing such issues. This question calls upon the best of our collective wisdom. Perhaps the answer lies in finally merging Western knowledge with that of Aboriginal colleagues and elders and calling upon the lessons of the past to guide us in this journey to slay the "dragons" that lie in wait in those uncharted lands.

Our Aboriginal colleagues have been articulate in expressing their hope for a child welfare system that works for them. Their intent is clear and their objective is sound. It is also clear that the path to this objective is strewn with overt 
obstacles, hidden dangers, fog laden forests, impish impediments, and lurking lunatics. Some of these may be easier to spot than others. They include explanatory discussions of oppression, colonialism, Euro-centrism, domination and exploitation. The impacts of systemic poverty and racial discrimination should be well known and require little elaboration. A Federal government that has much practice in evading its full responsibility and Provincial governments that collude with this evasion only perpetuate the dilemma. Canada's citizens are best bemused and at worst hostile toward Aboriginal people who are often viewed as benefiting from the largesse of "our tax dollars."

Meanwhile Aboriginal communities continue to lose their most precious resource, their children, to child welfare systems that, more often than not, end up destroying their affiliation with their people, leaving far too many as lost souls whose ultimate destination may be the street or jail. Our 'well-meaning' interventions seem to, only too rarely, create happy, healthy, and productive adults. Some appear well but end up not belonging anywhere or to anyone, disconnected from their communities of origin and not belonging to their adopted community (Richard, 2004).

To what do we attribute such tragedies? Research conducted under the umbrella of the "Making our Hearts Sing" (MOHS) initiative in Alberta has begun to reveal the impact of residential schools and foster care for Aboriginal children. As we reflect upon the seemingly inexorable flow of Aboriginal children into nonAboriginal care, it is imperative to reflect upon our professional beliefs and assumptions in the delivery of child welfare services. It seems evident that current service and programmatic paradigms exist in direct opposition to traditional Aboriginal ways of thinking. This has arisen repeatedly in our research, and will be described in greater detail later in this paper. It seems timely to reflect upon the foundations of such programs as Aboriginal people seek return to traditional worldviews and values to replace what they view as unworkable program models that only worsen their current situation.

\section{Prevailing Western Paradigms}

Several Western thinkers have influenced our society dramatically over the past few centuries and are worth revisiting in light of their legacy. This seems especially important at a time when Aboriginal people are seeking a return to holistic values at the interpersonal, ecological, and spiritual level. Such values stand in direct contrast to prevailing models of child welfare practice. These models are based upon our relatively recent Western paradigms that have greatly contributed to the development of modern civilization. It is suggested that this progress has been procured at a high price. The following brief overview reminds us of our philosophical origins.

European thought was strongly influenced by the Cartesian dichotomy of mind and body, which led man to view himself as an isolated ego within a material body, which he was then to control. Descartes fundamentally affected the western world by dividing nature into two separate and independent realms: that of mind and that of matter. This allowed scientists to treat matter as dead and separate from themselves, and to see the material world as a multitude of objects assembled into a huge machine. Newton held this mechanistic view and constructed his theory of mechanics on this basis, making it the foundation of classical physics. 
While the Cartesian division and Newton's mechanistic worldview may have been beneficial in the development of technology, they have not been as applicable to the world of human relationships and services. Existential philosopher, Gabriel Marcel (1949), goes so far as to propose that our undue faith in technology has led us to a form of 'pantechnicism' - an abuse of the methods of science - by extending it into areas to which they do not apply, such as those of interpersonal relations, philosophy and ethics.

Taylor (1922) established the School of Scientific Management in the early 1900s, which advocated the scientific method as the most efficient way to work. It consisted in shifting all responsibility for the organization of work from the worker to the manager, selecting the most competent person to do the work, training the person to do the work efficiently, and then monitoring performance to ensure that the work was done correctly. This formed the basis for the creation of assembly line production. Despite his contribution to economic prosperity in the Western world, Taylor ended up a hated man and eventually went mad as people reacted to an increasingly dehumanized work environment. His influence continues and extends to the complex and often fragmented system of social services we have today.

Weber (1947) was the first to study and describe the characteristics of bureaucracy. Most remembered for his study of the positive aspects of bureaucratic arrangements, Weber also studied this phenomenon out of concern for the negative implications he foresaw. He worried even then about the inability of such systems to respond to changing circumstances, the dangers of a mindless and unquestioning bureaucracy and the potentially dehumanizing effects on staff, especially those who worked at the lowest levels of the organization. The child welfare agencies formed in the twentieth century inevitably reflected these prevailing paradigms as the most efficient ways to organize work, becoming part of what Morgan (1986) describes as an inevitable societal movement toward increased mechanization, specialization and bureaucratization. Since that time the Child Welfare system has increasingly adopted the bureaucratic and management practices of that era. While these practices have generated great benefits for humankind, we suggest that they have their down sides. The pursuit of scientific and professional solutions to the problems of people seems at times to have estranged child welfare from the communities and the people it serves. While important gains were achieved by the application of scientific and rational approaches to complex social conditions, have we lost the balance that is necessary between community and bureaucratic systems? In the absence of any other familiar models and because of the constraints imposed by funders and policy makers on Aboriginal communities have they been forced into a paradigm alien to their innermost beliefs and values? Has our embrace of the bureaucratic paradigm with its recurrent themes of domination and rationality inadvertently aborted the Aboriginal search for autonomy and self-determination?

We believe these to be important questions for all of child welfare. Hardly a day goes by without a major child welfare crisis somewhere in the Western world. Most often there are calls for procedural solutions or resources to minimize the repetition of 'errors' that call attention to 'deficiencies'. Child Welfare reviews leave a legacy of increased paperwork reporting and information requirements, to 
the point where the time spent on casework with clients is now far less than the time needed to document their interventions. New procedures, safeguards, protocols, and training and information requirements are promoted. New tools are introduced: risk assessment, sophisticated information systems, rigid timelines, and greater specification of responsibilities and reporting requirements, and new legislation to name only a few.

These changes and revisions seem to be more concerned with achieving the institutional role of gatekeepers to scarce resources than guaranteeing quality children's services. This seems to validate Weber's fear that growing areas of life would be subjected to decision-making according to technical rules, diminishing creative thinking and self-direction on the part of its members. The key dimensions of routine and hierarchical decisionmaking might eventually replace discretion, spontaneity, and personal moral choice. Studies about client and staff experiences with child protection services suggest that at least some of these fears have become reality in our child protection services (Lafrance, 2001).

Modern child welfare services are seen by many as hierarchical, overly specialized, and procedurally bound. This can result in service models that look for pathology rather than strength and that seek to maintain the status quo rather than to seek structural change. RalstonSaul (1995) provides some early alerts to the parade of ideology to which the human services have been subjected: assertions are made as truth; there is contempt for considered critical reflection and a fear of debate. There is a need to counter this tendency. We need forums in which service recipients, service providers, policy makers, and academics can challenge and support each other to create more responsive services. The "Making our Hearts Sing" initiative in Alberta (MOHS) is finding signs of hope in Aboriginal communities engaged in a healing process. Youth are being asked to contribute to their community and to help other youth, and clients and front line social workers are beginning to be heard. Most importantly, the Elders are increasingly recognized as an important source of wisdom and experience. Important changes are taking place in Aboriginal communities - changes that must be attended to and carefully nurtured, as they may have the key for all of child welfare. We must be mindful that in spite of their best intentions, there are forces at play that work against their interests. Some overt, some subtle, and others are so deeply engrained in our psyche that we are barely conscious of their presence.

\section{Reflections - Past and Present}

If we are to break the cycle of destructive practices towards Aboriginal people that has nearly decimated their culture and their way of life, it seems important to reflect on Indigenous peoples' experiences with oppression and colonization over the past 500 years. This calls for an examination of deeply held assumptions, values, and attitudes that can have a sometimes unconscious, but always powerful impact on our behaviors. An alternative perspective is needed that builds greater understanding of the Aboriginal world view. The importance of reflection on this matter becomes even more important as we begin a new discourse initiated by such endeavors as the Reconciliation initiative begun in Niagara Falls in $2005^{1}$.

It then seems relevant to revisit prevailing paradigms in which world views are expressed. Henderson (2000, p.12) compares the development of scientific paradigms with those that take place in the social sciences 
as "context." As a paradigm reflects current scientific thought about the natural world, "context" reflects current social, political, and legal thought about human social order. He cites Roberto Unger, a Brazilian legal scholar who asserts, "If context allows the people in it to discover everything about the world that they can discover, then it is a natural context. If the context does not allow such movement then it is an artificial context derived from selected assumptions" (p.14). Many Aboriginal people have concluded that their survival lies in rediscovering the context that sustained them for many thousands of years before it was replaced with an artificial context. Unger's central thesis is that human empowerment depends on our ability to reduce the distance between what he calls context preserving routines (laws) and context transforming conflict. Human empowerment relies on the ability to (re)invent institutions and practices that manifest context revising freedoms. An improved understanding of the artificial context that has governed much of Aboriginal life may help inspire the creation of an alternative and more natural context and reduce the residue of colonialism; domination and oppression. Ultimately, this may construct a more just and equitable society.

Afro-Caribbean psychiatrist Frantz Fanon (Cited in Henderson, 2000) has defined colonized people as:

... every people in whose soul an inferiority complex has been created by the death ... of its local cultural originality... which finds itself face to face with the language of the civilizing nation that is with the culture of the mother country. The colonized person is elevated above his jungle status in proportion to his adoption of the mother country's cultural standards. He becomes white as he renounces his blackness, his jungle. The tensions between cultures and languages, inferiority complex, the assimilative choice are all elements of the brutal, subtle brutality of colonization (p.28).

This seems to reflect the conundrum that faces Indigenous people who wish to succeed in a prevailingly white society. We may be more politically 'correct' today, but we suggest that the following contains assumptions and beliefs about Aboriginal people in Canada that continue to exert greater influence than we may realize. The following summary of proceedings of a Joint-Church Delegation of the Indian and Eskimo Residential School Commission (1930) reveals some assumptions and beliefs that underlie an important policy discussion about the education of Aboriginal people that may be worthwhile revisiting (RG 10, volume 6730, file $169-62$, pt. 2). The following described the prevailing belief about the perspective of Aboriginal people on the superiority of European culture vis-à-vis the forces of nature.

... so far as the Indian himself is concerned, he has already seen with his own eyes that many of the white man's ways are superior to his own. He has seen, for instance, that the white man's methods and education have given him control over many of the forces of nature and over many of these circumstances of life (p.1).

The delegation then describes two fundamental and contradictory assumptions about Aboriginal people that had far reaching implications for shaping policy on Aboriginal education;

... further as to the question of providing the best system of education for the Indigenous people of this country is one which had to be faced in other parts of the world where superior races invaded and possessed the territories occupied by similar peoples. Careful consideration is demanded in 
connection with two other important factors which have a direct bearing on the subject. The first is as to whether the Indians existing need is to be taken as the foundation upon which our education is to be built and by which it would, in effect, be limited. Two, are we to assume that the white man's education is the most perfect yet devised by the ingenuity of man and impose that education upon them without necessarily considering whether, in fact, it is the best, the form best suited to their capacity or their needs. Both methods have been employed in dealing with various primitive peoples in other parts of the world and as might be expected, with various results (p.1).

The policy decision focused on a choice between building on the strengths of Aboriginal people and "grafting onto the deeply rooted stock of what already exists" or assuming that there was nothing worth building on. It was acknowledged, "The Indians successfully occupied this continent for 12,000 or possibly, 20,000 years ... they have displayed unsurpassed human qualities of loyalty to unseen powers and adaptability to the practical; have a living past capable of energizing their present and "any system of education which destroys all their faith in their own institutions and traditions will create in them, a sense of permanent inferiority and an unfortunate belief that everything which is peculiarly your own is not only worthless but an obstacle to progress" (RG 10, volume 6730, file 169-62, pt.2). Others contended that the only hope for progress among Indigenous people lay in "the complete application to their condition of the western consciousness, experience, knowledge, and skill." It was only thus that they could benefit from "the education needed to advance them to higher levels of civilization and to enable them to use to their own advantage, the natural resources which surround them." The policy positions were clear (p.2).

Interestingly and in contradiction to the decision ultimately taken, the church societies considered the traditional qualities of Aboriginal people as worth preserving. These are quoted verbatim:

1. "The quality of loyalty to family and friends which is capable of expansion into loyalty to a wider circle.

2. The deep love of children from which can be developed the strong desire to help the children of the race to be well-born.

3. The generosity and hospitality which are outstanding characteristics of the Indian races which may be developed as some of the finer elements of social living.

4. The traditional quality of courage and admiration of brave leadership and which can be used to spur the young Indian on in the face of discouragement and the hard grind of monotonous routine.

5. The engrafted dignity and serenity of the leaders of the race and which should be preserved as a help in restoring to the hectic world in which we live, the poise and calm of which we have been robbed by our numerous mechanical inventions" (RG 10, volume 6730, file $169-62$, pt.2, p.3).

Regrettably, such insights did little to challenge prevailing assumptions and beliefs that held the Aboriginal people to be in need of civilizing and Christianizing. One cannot help but wonder how differently the lives of Canadian people might have evolved if such beliefs had prevailed in the education and care of Aboriginal children. Ironically a residential school study in Saskatchewan (Caldwell, 1967) describes the experience of Aboriginal people 
in the residential schools of Canada that flowed from this policy decision. The residential school system failed to meet the total needs of the child because it failed to individualize, using sleeping, eating, recreation, academic training, spiritual training, and discipline to force compliance rather than developing the children. This was clearly a system designed to overlook the qualities that been so clearly acknowledged. Yet in spite of efforts to extinguish Aboriginal people and early predictions of their demise, they have been able to sustain much of their way despite ongoing assaults for the past 500 years.

While important policy and legislative changes have been made to support greater autonomy for Aboriginal child welfare programs in the recent past, we are suggesting that this is an essential, but not sufficient condition for selfdetermination in the delivery of such services. Historian Lise Noel (cited in Henderson, 2000, p.29) reminds us that systemic colonization is grounded in intolerance. This intolerance comes from unconscious assumptions that underlie "normal institutional rules and collective reactions." It is a consequence of following these rules and accepting these reactions in everyday life. In systemic colonization, Noel suggests that no single source of oppression or demeaning can be assigned causal or moral primacy. These are imbedded in the consciousness of all and so engrained in our day to day lives that if the oppressed cannot point to any single form of oppression, then the oppressor and his consciousness become invisible. In short, if fundamental change is to take place, we need a collective and intensive reflection on what is taking place in our souls.

Young (cited in Henderson, 2000, p.30) poses a conundrum for those who are assigned to the dominant groups of society.

(C) Jean Lafrance and Betty Bastien
The oppressor has no apparent existence. Not only does he not identify himself as such, but he is not even supposed to have his own reality. His presence is so immediate and dense and his universe coincides so fully with the Universe that he becomes invisible. Rarely seen, rarely named, he is unique nonetheless and having a full existence as the keeper of the word. He is the supreme programmer who confers various degrees of existence on those who are different from himself...as the embodiment of the universal, the dominator is also the only Subject, the Individual, who never being considered to belong to a particular group can study those impersonal categories of the population who pose a "problem", represent a "question", constitute a "case" or simply have a condition".

The complexities involved in reconciliation with Aboriginal people by members of the dominant group are no simple matter. We are finding that to support Aboriginal self determination in the development of policies and practices that are in keeping with Aboriginal traditions and beliefs calls for an uncommon degree of humility and a high degree of receptivity to different ways of thinking. This task is further complicated by the reality that most Aboriginal professionals have been educated and socialized in mainstream systems for practice in child welfare systems. While many are gaining greater understanding of their heritage, they cannot but be influenced by the educational and socialization system to which they have been exposed, resulting in what Little Bear (2000) calls "jagged colonialism." Aboriginal communities are being challenged to become even more aware of their internalized oppression and to create social work practice that is congruent with their traditional worldview and values. This calls upon the best of the community's collective wisdom. For those who wish to support community efforts 
perhaps the answer lies in finally accepting the wisdom of Aboriginal colleagues and elders as our guides in this journey. Carniol (2005) describes how Aboriginal social work practitioners and tradition teachers have influenced him as a teacher and practitioner.

They have influenced me in a very profound way. One of my teachers in this area is an Anishnabe Elder. Her Aboriginal name is Waubauno Kwe. Her English name is Barbara Riley. I first met her at a workshop and as I heard her speak and saw the way she interacted with the workshop participants, I found myself being very open to the kind of teachings that she was providing. I discovered that Aboriginal cultures are very sophisticated and intricate. I was amazed at the extent to which I had internalized the privilege of mainstream culture that has devalued and created false images of Aboriginal culture. I am very grateful to her for her willingness to become one of my mentors. She is responsible for my traveling along a road where I learned much more about Aboriginal world views, and realized that when it comes to helping people, there is a whole area of wisdom that Aboriginal culture can offer us (p.2).

The complexity of understanding a different life perspective can be daunting when the dominant society so prevails that we are unaware of our contribution to the oppression of Aboriginal people. This is evident when new knowledge derived from work with Aboriginal people fails to resonate at a sufficiently deep level to create greater understanding. Our partnerships demand an authentic sharing of knowledge and an intensive collaboration in creating new paths. Mutual respect and recognition of the integrity of the 'natural' Aboriginal cultural context must be our guides as we journey together.
The "Making Our Hearts Sing" initiative in Alberta clearly tells us that community perceptions about new solutions to child welfare issues in Aboriginal communities must begin with human rather than technocratic responses. Our collaboration premised on the assumption that the cultural integrity of First Nations conflicts with prevalent approaches to the delivery of child welfare services. The holistic and flexible models favored by Aboriginal families and communities differ greatly from the specialized and often rigid practice models that prevail in most of child welfare. Much as the collective ignorance demonstrated by global unconsciousness to the current ecological and economic sustainability crisis, there seems to be a collective inertia in response to the historical and contemporary structures of violence toward families and children. We are learning from the stories gathered in our work that the outcomes of current child welfare interventions for many Aboriginal children have been abysmal and in some respects worse than those of the residential school system. Survivors from both the residential school system readily admit that those who were placed in foster care as the only Aboriginal child in a white community were worse off because they were deprived of the companionship of their peers for most of their childhood. It is suggested that the fundamental reasons contributed to this tragedy continue to be present. These include a lack of funding to support and sustain Aboriginal families in their communities, and the primary allocation of funds that supports the break up families and the placement of the children with non-Aboriginal caregivers. As stated by John S. Milloy in a presentation at a conference on Reconciliation in Child Welfare gathering held in Niagara Falls titled "How Do Bad Things Happen when Good People have Good Intentions?" 
Doing good is apparently better than doing nothing well - and so hangs the tale of the residential school system, and the child welfare system too, which could only afford child protection (removal of children from their families) rather than prevention activity (Reconciliation Movement, 2006).

This has been a fundamental flaw since the promulgation of the Indian Act. In the beginning the Federal government provided insufficient funds to religious organizations to serve Aboriginal children removed from their homes while providing minimal resources to maintain children in their homes and support their families. This same policy direction laid the foundation for the " 60 's scoop," as provincial authorities removed children from their communities and federal authorities limited their contribution to reimbursing the provinces for out of home care by primarily white caregivers. The policy remains essentially unchanged today in spite of delegated Child Welfare authority to First Nations. Canada pays full costs to First Nation agencies for the removal of children and precious little for supporting and preserving families, perpetuating a legacy that continues to escalate. In this sense the only change that has taken place in over 130 years has been the players. We have gone from missionaries, Indian agents, Royal Canadian Mounted Police to provincial social workers and to First Nation Agencies. Until fundamental change occurs at the fiscal and program policy level with the Federal and Provincial Authorities we condemn many well intended people to a cynical system that refuses to contemplate the havoc it continues to create and the resulting social and economic costs.

When the expression 60's scoop was first coined based on information compiled by Johnson
(1983), there were about 3000 Aboriginal children in care. In spite of the best efforts of many the numbers have escalated to 22,500 First Nations children in care in all of Canada (Bennett \& Blackstock, 2002). They place this figure in context by indicating that in 1940 there were approximately 8,000 First Nations Children in residential schools when these were in full operation. What can be done to curtail such an alarming trend when the programmatic and legal solutions underway are failing to staunch the loss of children to family and community? Need we not look in an entirely different direction?

As Aboriginal people seek to renew and invigorate their own spirituality as a source of strength, perhaps social work should also look deeply into its own spiritual roots. Zapf (2003) suggests that as a profession seeking to improve its status as evidence based discipline, social work may have avoided spiritual issues because they were perceived as unscientific. This pattern is changing as social workers express a renewed interest in spirituality. Zapf (2003) cites Drouin (2002, p.34) who attributes this renewal to "a longing for profound and meaningful connections to each other, to ourselves, and to something greater than ourselves" that has arisen because the Western mindset of individualism and materialism has ruined the environment and destroyed community. $\mathrm{He}$ sees evidence of "growing spiritual longing" in social work practitioners, in clients, and in Western society as a whole (p.36).

Zapf (1999a) suggests that while some authors have attempted to include traditional knowledge or "Aboriginal theory" as part of the knowledge base for mainstream social work practices any assumption of traditional knowledge as just another theory base disguises a fundamental 
difference in world view. Morrissette, McKenzie, \& Morrissette (1993) express the essence of this difference as follows:

While Aboriginal people do not embrace a single philosophy, there are fundamental differences between the dominant EuroCanadian and traditional Aboriginal societies, and these have their roots in differing perceptions of one's relationship with the universe and the Creator (p. 93).

Hart (1996) compares Western and Aboriginal approaches as follows:

Western models of healing separate and detach individuals from their social, physical, and spiritual environments, isolating "patients" for treatment purposes and then re-introducing them into the world. Traditional healers are concerned with balancing emotional, physical, mental, spiritual, aspects of people, the environment, and the spirit world (p. 63).

Social work has begun to incorporate spirituality as part of its knowledge base and practice foundation. Zapf (2003) warns of the danger in limiting our understanding of spirituality to a component of the person, pointing to Aboriginal social work and traditional healing that are founded on a spiritual sense of interconnectedness. He asks if spirituality might not be a key to expanding our understanding of the person/environment relationship, the profound connections between ourselves and the world around us.

\section{PART II - POTENTIALITIES \\ Making our Hearts Sing}

The Making our Hearts Sing (MOHS) Initiative in Alberta took up this challenge by aiming to build collaboration among child welfare stakeholders and Aboriginal communities to examine issues relating to child welfare in their communities and create innovative, effective and practical approaches to child welfare that are more in keeping with traditional Aboriginal worldviews and may contribute to reconciliation, healing and increased community capacity. To this end, the research represented collaboration between the Alberta Ministry of Children's Services, the University of Calgary Faculty of Social Work, the Blood Reserve, the Sturgeon Lake Cree Nation and Region 10 (Métis Settlements) Child and Family Services Authority.

\section{MOHS Methodology}

Appreciative inquiry was selected as the guiding methodology for the study, as it provided a good fit with the research goals and Aboriginal culture. First, Appreciative inquiry moves away from a problem focus to a participatory, strengths perspective. Through this approach, people collectively celebrate their accomplishments, build on their successes and act upon their dreams and wishes for the future (Elliot, 1999; Hammond, 1996). This strengths approach is consistent with calls to move away from deficit approaches to understanding Aboriginal communities towards approaches that highlight the competence and resiliency of Aboriginal people and can help to design new and culturally-meaningful approaches to community needs (McShane \& Hastings, 2004).

Second, the Appreciative Inquiry process is a participatory approach that provides a voice to Aboriginal perspectives, which have traditionally been silenced (Sinclair, 2003). Third, storytelling is the primary data collection approach of Appreciative Inquiry, a practice that is congruent with the Aboriginal oral tradition. Storytelling has also been conceptualized as 
a consciousness raising type of activity that allows people to relate to each other, develop greater self-awareness, break the silence, and contextualize their experiences from their own worldview (Abosolon \& Willett, 2004). In summary, the Appreciative Inquiry approach provides a holistic and participatory approach that values multiple ways of knowing and working collaboratively from a strengths perspective towards a shared vision. It was hoped that this approach would help generate community empowered approaches to child welfare that could serve as exemplars for other Aboriginal communities.

\section{Data Collection}

Storytelling or unstructured interviews in the form of gatherings or sharing circles were used to collect data from the project. Simply put, a sharing circle begins with an open-ended question, in this case the research questions and gathering objectives. Then, each participant in the circle has the opportunity to share his or her perspective on the question or issue in a round robin format. The gatherings focused on the implications of the legacy of residential schools for child welfare, developing community and youth leadership, and sharing and learning from the gatherings. The specific focus of the gatherings in each community varied according to community needs and interests. Over 250 community members, leaders, professionals and elders were involved as participants in a total of seven gatherings in the three communities. The gatherings and stories were audio recorded and transcribed, and in many cases, also filmed.

The community was approached by the project steering committee, and a meeting arranged with appropriate community leaders, including elders, for open discussion about the research and partnership potential. Thus, appropriate protocols for collaboration and community involvement were established with each community. The Kainai Legislative Initiative of the Blood Tribe became a major community partner in the project. The Initiative's mandate is to have jurisdiction and law-making authority with respect to Child, Youth, and Family Services in their community. The project provided an opportunity for collaboration and the advancement of their work in establishing relevant and culturally appropriate services to their community. Building on their earlier work, this research project focused on the question, "to improve the utilization of traditional knowledge in service delivery, we need to......" Three gatherings were conducted using an open spaces facilitation approach, which engages participants for the collection of ideas and promotes a creative thinking process. The first two gatherings focused on data gathering in implementing traditional knowledge in the child welfare services and the last session celebrated and received recommendations primarily from the elders. The gatherings were extremely successful and approximately 170 people participated.

MOHS found considerable synergy between the voices of these authors such as Zapf and Hart, and the messages derived from community participants' renewed vision for child welfare services. Existing programs are not working as well they could, as indicated by the rising number of Aboriginal children in care. Many are concerned that the child welfare experience may inadvertently parallel the colonial experience of residential schools and may have similar long-term negative ramifications for Aboriginal communities. The impact for those who have experienced either or both systems is evident in the alarming statistics of Aboriginal people's continued trauma as reflected by high rates 
of suicide, poverty, substance abuse, family violence, family breakdown, school drop out, and escalating child welfare caseloads in Aboriginal communities.

While many Aboriginal child welfare agencies are seeking models of practice that are more consistent with their worldviews to counter these trends, there is a dearth of "new" models that incorporate "old" ways to respond to an increased understanding of the impact of colonization, residential school experiences and the 60's scoop on Aboriginal communities and families. A consensus is evolving many Indigenous communities that new approaches to child welfare intervention and prevention founded on a framework of analysis that provides an understanding of the history and current reality of Aboriginal people and culture are needed. Such a new framework is a necessary foundation to facilitate Aboriginal ownership and leadership in child welfare.

The challenge is to learn from joint efforts with Aboriginal communities that will not only create new insights, but new knowledge that can be readily applied to real world situations. MOHS took up this challenge by building collaboration between child welfare stakeholders and Aboriginal communities to create innovative, effective and practical approaches to child welfare that are more in keeping with traditional Aboriginal worldviews and that contribute to reconciliation, healing and increased community capacity. The questions guiding the study were focused on the historical effects of the residential school experience on the identity of Aboriginal children, families and communities and a comparison with the effects of placement in child welfare services on the identity of Aboriginal children, families and communities.

The following section summarizes some of the work, insight and learning from this collaborative endeavor with the Blood Reserve in Southern Alberta. The creation of a new vision is not without its challenges. On the one hand, there is a strong and continuing desire among many Aboriginal people and their allies to build upon traditional Aboriginal strengths and values such as; courage, respect for each other and for nature, the oral tradition and the wisdom of the elders, a deep connection with each other and mother earth, a consistent application of spirituality to all of life. Cultural camps and some models of practice provide concrete examples of the power of these concepts to improve daily life.

On the other hand, the loss of culture and tradition resulting from colonisation continues to affect the lives of Aboriginal people, and 'Western' people are often unaware of the oppressive impact of their assumptions, beliefs and attitudes toward Aboriginal people. The ultimate objective of the MOHS initiative is to create an opportunity for conversation and understanding. Sahtouris (1992: p.1) a planet biologist, tells of an ancient prophesy that illustrates more fully the nature of the conversation;

Within the ancient Hopi Indian Prophecy is told the history of the Red and White brothers, sons of the Earth Mother and the Great Spirit who gave them different missions. The Red Brother was to stay at home and keep the land in sacred trust while the White Brother went abroad to record things and make inventions. One day the White Brother was to return and share his inventions in a spirit of respect for the wisdom his Red Brother had gained. It was told that his inventions would include cobwebs through which people could speak to each other from house to house across mountains, even with all doors and windows closed; there would be carriages crossing the 
sky on invisible roads, and eventually a gourd of ashes that when dropped would scorch the earth and even the fishes in the sea. If the White Brother's ego grew so large in making these inventions that he would not listen to the wisdom of the Red Brother, he would bring this world to an end in the Great purification of nature. Only a few would survive to bring forth the next world in which there would again be abundance and harmony.

Indigenous elders tell us that the time for this to happen is near and that the need for dialogue is urgent and compelling.

It seems clear to us that the adoption of an overly bureaucratic and legalistic paradigm has greatly rigidified practice by the introduction of overly specialized roles, top down and fiscally driven policies, increasing disconnection from community, overly prescriptive standards and other trappings of technologically based approaches. These have served to distance child welfare agencies from those they serve. Yet these models are often forced upon Aboriginal community service providers, further impairing the community aspirations for greater autonomy and self-determination. The communities involved in MOHS initiative are clear about the essential values and philosophy that must guide the development of programs and services. They stress the importance of shared parenting and community responsibility for children, the importance of language as a source of renewed culture, knowledge of history and tradition as an essential element of identity, the importance of kinship and connection to each other and a respectful approach to the planet. The problem is that the chasm between what Aboriginal communities envision and the realities of funding and policy restrictions are enormous. The gap in our understanding

(c) Jean Lafrance and Betty Bastien is vaster than initially envisioned by some of the principals in MOHS. While we continue to be hopeful of finding new ways as to serve families and children as envisioned, we are less naïve than we may have been a year ago. Little Bear (2000) speaks to the collision of jagged worldviews and helps us to understand the hazards of understanding each other. The 'western' worldview is more linear than holistic, hierarchical and specialised rather than generalised, more materialistic and selfinterested than sharing, less concerned about relationships and kindness than competitiveness, more aggressive than respectful, and more focussed on external sources of control and authority than on the development of internal controls. Therein lays the challenge in creating greater understanding.

Our work thus has brought us further along in our journey with communities, planners, practitioners, leaders and elders to find this understanding, but we have much more to learn. The communities' views of services that would help them can be far removed from current models of practice. The following illustrate some of the themes that arose in community meetings. It is important to recognize the extent to which the assumptions, values and beliefs upon which they are based differ from the prevailing approaches described in Part I of this chapter and their inherent potential for positive change. While they are distant from many of mainstream child welfare, we believe that they offer fundamentally human approaches that may surpass our current (over) reliance on technocratic solutions.

\section{Messages from community}

The most important message from the community gatherings was that the incorporation of cultural practices that support 
important familial and community kinship systems is critical to a process of recovery. In our view, this has two prerequisites. The first is that Canada and the Provinces must own their responsibility to change funding and legislation in ways that mitigate the impact of colonial policies on Aboriginal communities, families, and children, and, allow for a higher degree of self-determination in charting their collective future. The second is that Aboriginal people must intensify their awareness of the depth of colonization and its impact on their communities, especially on the children and youth who remain at high risk. Unless these are confronted, the disconnection from Aboriginal beliefs and values and the resulting devaluing of their child rearing and human development practices can only be perpetuated. An approach to child welfare consistent with the Aboriginal culture would focus on family and collective human relationships. It would strengthen a collective approach to child care responsibilities that encompasses the cultural continuity of a people. Cultural continuity is the cornerstone for the amelioration of the most negative and destructive impact of colonization. Socialization and educational theories and practices are fundamental to the survival of parenting practices for any cultural and societal group. In fact, they are essential to the group's meaning of life and the purpose of their existence. These essential elements must be supported to interrupt the cycles of lateral violence in First Nations communities.

The major clusters of themes that emerged from these gatherings express the cultural and societal crisis of the community and its understanding of the path of recovery. These clusters are: (1) the recovery and affirmation of cultural and societal values (way of life) and (2) the structural violence of colonial policies and practices.
The first cluster of themes focused on identity, relationships, and the interconnectedness of language with a way of life supported by the teachings of the elders, the passing on of stories which are their knowledge system (education), and the importance of kinship systems as important components of responsibility for child care, socialization and education. The second cluster of themes reflected the realities of their lived experience with colonial violence, the structural violence of poverty and marginalization, unemployment and racism, with the attending issues of substance abuse and lateral violence among community and family members

\section{Cluster One - Themes relating to the recovery and affirmation of culture and a way of life}

\section{Making a path for children so that they can live}

The cultural identity of the tribe is the most significant component in revitalizing and affirming traditional methods of child care. Tribal identity is based upon a common worldview of the nature of human beings, and their relationship to nature. These primary relationships shape the nature of relationships within family and community. The incorporation of the physical and metaphysical world, family, and ancestors is fundamental to kinship relations. The separation and disconnection of people from the essence of their existence has been the most profound impact of residential schools and child welfare systems, as the unity and wholeness of an all inclusive universe is at the heart of Aboriginal peoples' connection to their cultural and social identity.

The community told us that the teachings and stories must be once again told to the children, and that "our children must know who they are." 
The children must be given their cultural names; this is what connects them with the universe, the land, their community, and their family. Most importantly, this is what provides them with a place from which to securely participate in the world as they draw on the kinship relations from which their names are derived. Reuniting and affirming these relational connections and the responsibilities imbued in these relationships is the essential function of cultural and social identity.

The stories must be told in the original language. Language reflects the philosophical system of the people and evokes a relational perspective which mirrors their sacred world (Bastien, 2004). It reflects the meanings ascribed to existence, the purpose of relationships, and the responsibilities inherent in these connections. It provides a way of interpreting the world in which they live (Bastien, 2004). Language guides the epistemology and pedagogical practices of the Tribe; it is instrumental in creating knowledge and creating reality (Bastien, 2004). It is the medium for incorporating knowledge systems and creating identity. New responsibilities, organizational structures, programs, and services can flow from this connection to traditional knowledge and the responsibilities of the collective. Inclusion and connection are integral to the way of life and identity of indigenous people and can serve to inform revitalized programs and services. More specifically, participants stressed the importance of revisiting education by:

- Incorporating indigenous methods of research.

- Recording and documenting traditional knowledge.

- Rethinking educational programs.

- Involving the community in changing the social environment.

(c) Jean Lafrance and Betty Bastien
- Making language education mandatory.

- Educating young parents.

\section{Collective recovery through participating in indigenous culture}

The disruption to Aboriginal family and community life is evident in the fragmentation of the way of life and worldview of the community. Affirming attachment to family and community life, parental bonding, kindness, and nurturing of children as essential components of service and program delivery is reflected in the principles of Aboriginal culture. Recent scientific findings about the nature of reality reveal that everything is related to everything else in the universe. In other words, material objects are no longer perceived as independent entities but as a concentration of energy of the quantum field. This is not new knowledge to indigenous people who have always understood the universe to be the indivisible whole that quantum physics now understands. This indivisible wholeness of universe is the source of Aboriginal spirituality. The cultural principles and assumptions of Aboriginality, a way of life based on spirituality as the source of all relationships, calls upon all people to assume responsibility for all relationships.

An Indigenous human development approach based on collective responsibilities must guide the development of programs and services for families and children. It must begin with those who are most vulnerable and who contain the greatest hope for a new era for Aboriginal people, the children. The participants were adamant that language is mandatory and that their stories form the foundation of knowledge systems, of inclusiveness and harmony, and of the knowledge by which to guide the interpretation of experience. Language provides the forum and medium for speakers to call into 
existence a world of relationships and alliances. This calls for a social and spiritual order that places them in a universal social system in which to live their lives. This social system in its essence consists of relationships held together by an affinity to all of life and an intention for survival. Collectively, it is being responsible for the health and peace of all. Communal well being is a collective sacred responsibility and is the essence of the purpose for living. Children must be taught about their ancestors, their history, and their alliances through story, ceremony, and language. Cultural continuity means integrating tribal ways into everyday life, and it is in this experience that the identity of Indigenous people can best be understood.

The participants valued coming together in feast and gatherings to renew and revitalize communal values and the affinity of kinship systems. Such gatherings are the traditional methods for gathering and promoting collective knowledge and wisdom. They renew and strengthen collective responsibility and through consensus call for action to address the challenges of the day. Gatherings revitalize traditional ways for strengthening the affinity of collective and family ties, affirming and utilizing knowledge building, decreasing external dependencies, developing indigenous leadership and practices, and creating new sources of knowledge for recovery.

Spirituality is expressed as an ontological responsibility for strengthening family and kinship alliances that create a more sustainable and thriving community, with a focus on the wisdom of the elders and the potential for a more hopeful future for children and youth. It is based upon traditional teaching and learning, with each person taking responsibility for the various roles of family and community. It is a method of forging new alliances, kinships and coming to know your relatives. Spirituality is having respectful care for family, elder, children, parents, and grandparents. Respect is striving to preserve the sacred nature of all relationships that life holds for every one and everything and between every one and everything. It is the "all my relatives" of the Tribe. This means to live in ceremony, to be respectful and to honor all relationships as the source of communal strength. Spirituality is living and being in a way with life which includes the sacred. The community stressed the importance of the following practices to support and affirm this more spiritual way of life:

- Spirituality expressed in sacred ways of prayer

- Smudging

- Teachings

- Positive attitudes

- Feasts and gatherings

- Involving men in a healing process as well

- Creating employment to increase selfreliance

- Taking responsibility for ourselves

- Education

- Knowing and living values

- Ceremonies

- Knowing relatives

- Creating harmony through traditional activities

\section{Living in ceremony demonstrates traditional} knowledge and teaching

The traditional teachings about collective responsibilities are the guiding principles for everyday living. They have a transformational impact on community life and social organization, and will improve the quality of life for all members. The hope is that families 
and community will have stronger connections because of a more culturally appropriate approach and the use of their indigenous language. This approach is based on coming together as a nation in a return to traditional teachings led by the elders and a process governed by communal values. Culture is expected to address many of the hurdles and challenges facing Aboriginal people because it is premised on the authenticity and integrity of traditional teachings, as opposed to a bi-cultural model. Implementing and affirming a cultural approach and reconstructing social systems and community collective responsibilities will form the context for education, research, and the creation of more culturally appropriate policies and services.

A comprehensive strategy guided by traditional principles of collective responsibility will under gird our community development approach. Community awareness, education, and training for Tribal entities are essential for the implementation of policy and program changes. The participants stressed the urgency of developing programs where youth are taught by elders and the importance of social workers trained in Aboriginal culture if the vision of the community is to be realized. The revitalization and affirmation of cultural identities is seen as the long term solutions for child welfare and youth at risk. This calls for "Aatsimihkasin" which means 'living in a sacred manner". The following themes sum up community perceptions of issues that must be addressed to deal with impact of structural violence.

- Long term foster care solutions

- Loving each other

- Creating laws to protect adopted children

- Looking after men's wellness
- Ensuring adequate housing

- Facing the reality of alcohol and drug abuse

- Bringing together youth and elders

- Building community

- Supporting families

\section{Cluster 2: Themes Related to the Structural Impact of Colonization and Collective Trauma}

The belief that power and control are central to mastery over other men and nature has guided the evolution of progress throughout the Western world. Colonialism has made Indigenous nations dependent as they were stripped of their own resources, means of economic sustainability and ways of knowledge production, leaving them a legacy of abuse and violence that rendered them powerlessness and demoralized. This continues in policies of apartheid, marginalization, economic dependency, stigmatization, and stereotyping, the very fabric of policies that initiated the process of genocide. The violence that continues on reserves in Canada includes overt physical violence, structural violence and psychospiritual violence. This violence terrorizes and re-traumatizes communities with programs structured on the very tenets of genocide; hierarchy, paternalism, patriarchy, power, control, rationality and empiricism. These tenets continue to fragment and isolate individuals, creating community despair and hopelessness that put on-reserve First Nations in seventyninth place in the world on the quality of life index compared with most Canadians who enjoy first place (Blackstock \& Bennett, 2002). Poverty, inadequate housing, and substance abuse are the leading factors for child welfare involvement (Blackstock \& Trocme, 2005). These factors have their roots in the structural 
violence of genocide and herein lay the fallacy for those who propose assimilation, adaptation, rehabilitation, reconciliation, accommodation, and advocacy as the only measures that need to be taken. The following factors were mentioned by community members as needing urgent attention and action:

- Poverty

- Adequate housing

- Protecting adopted children by keeping them connected to us

- Healing

- Alcohol Abuse

- Dealing with violence

- Respect for self

- Accountability for education funding

- Tackling the problem of gang violence

- Need for parental involvement planning needed programs

- Heath and well being of elders.

- Involving elders in programs and services.

\section{Authors' Perceptions of the Participants Responses}

- The participants that attended these gatherings have a clear understanding of the destruction of their way of life, and the current challenges of cultural continuity and collective survival.

- They also know that countering genocidal impacts and becoming a thriving community depends on the continuity of their cultural ways, kinship systems, and fulfillment of their tribal responsibilities.

- It is important to reinstitute social programs and structures that support kinship relational roles and responsibilities, as the continuity of kinship is critical to the wellbeing and survival of the community and the foundation of identity as Aboriginal people.

- Our challenge is to continue the collaboration and take steps to implement community recommendations

\section{Authors' Reflections on Participants' Responses}

1. Anti- colonial epistemologies, methodologies and pedagogies are required to affirm, rediscover and reconstruct the knowledge systems and social organizations of First Nation people. The epistemologies reaffirm cultural assumptions, the required validity for their lived experience. The context, reality, and aspirations of First Nation People must become integrated in research and knowledge production as opposed the current imbalance in power relationships that perpetuate the construction of knowledge based upon colonial assumptions that serve only to maintain the oppression.

2. Social work education and practice must develop curricula that support structural change and reflect anti oppressive practice by transforming conceptual frameworks in ways that support Aboriginal aspirations and right to self-determination.

\section{Next Steps for the MOHS Project}

- Work with Elders and ceremonialists in the construction of knowledge systems, conceptual frameworks and pedagogy for social work practice based on cultural integrity;

- Develop new program models based on community guidance that will be in harmony with the Aboriginal way of life and inform a new legislative framework; 
- Evaluate existing models that offer promise for broader application;

- Establish demonstration projects to test out and validate the community recommendations where needed;

- Develop curriculum for First Nation social work leadership and organizational change;

- Develop training programs for human services workers working with First Nation communities that pursue cultural continuity as their primary objective.

\section{POSTSCRIPT}

Our challenge is to find a greater balance between the well known tendencies of bureaucratic system which includes the notion that the "more perfectly the bureaucracy is 'dehumanized,' the more completely it succeeds in eliminating from official business love, hatred, and all purely personal, irrational and emotional elements which escape calculation. This is the specific nature of bureaucracy and it is appraised as its special virtue" (Elwell, retrieved July 27, 2006). According to Weber, because bureaucracy is a form of organization superior to all others, further bureaucratization and rationalization may be an inescapable fate. "Without this form of (social) technology the industrialized countries could not have reached the heights of extravagance and wealth that they currently enjoy. All indications are that they will continue to grow in size and scope" (Elwell, retrieved July 27, 2006).

Weber wrote of the evolution of an iron cage, a technically ordered, rigid, dehumanized society. Our challenge will be to avoid the pitfalls that Weber expressed when he speculated on the other future possibilities of industrial systems. Weber had a foreboding of an "iron cage" of bureaucracy and rationality, but he recognized that human beings are not mere subjects molded by socio-cultural forces. We are both creatures and creators of socio-cultural systems. And even in a socio-cultural system that increasingly institutionalizes and rewards goal oriented rational behavior in pursuit of wealth and material symbols of status there are other possibilities.

No one knows who will live in this cage in the future, or whether at the end of this tremendous development entirely new prophets will arise, or there will be a great rebirth of old ideas and ideals or, if neither, mechanized petrification embellished with a sort of convulsive selfimportance. For of the last stage of this cultural development, it might well be truly said:

'Specialists without spirit, sensualists without heart; this nullity imagines that it has obtained a level of civilization never before achieved (Elwell, Retrieved July 27, 2006).

This article is an attempt to bring together the perspectives of the authors who come from very different places and hopefully reflects the overall intent of "Making our Hearts Sing." It is not an easy journey to learn how the world appears to another person or people. But we believe it to be a necessary one. It is our hope that the message of Aboriginal people about the importance of spirit and heart in all of our lives is important in countering the negative tendencies of the 'iron cage' that we are too often creating. Lest it appear that we can easily change our perspectives in this journey through uncharted land, an ancient Amazonian legend provides a further source of wisdom. According to the legend, the blue-black Rio Negro and the creamy, caramel-colored Rio Solimões, run side by side, without mixing at the mouth of the Amazon River. The waters of the two rivers differ in temperature, clarity, 
density, and acidity, and continue side by side for miles before becoming the Amazon. Both rivers converge at one point but each retains its essential quality and characteristics. The resulting foam is new knowledge that would not exist if the rivers had not met. Our hope is that similarly the new knowledge generated by our coming together will allow Aboriginal and non-Aboriginal people to retain their essential qualities, while creating new solutions that will better serve all children and families.

\section{Endnotes}

1. The Reconciliation Initiative seeks to advance understanding the impact of child welfare interventions on Aboriginal families and communities in Canada and the United States, as well as examining the values and beliefs that underlie Indigenous and mainstream approaches to child welfare, and to identify the principles for a renewed approach to child welfare respecting Indigenous children at national and local levels. In an effort to make a difference for Indigenous children, youth and families over 200 leaders in child welfare from Canada and abroad, gathered in Niagara Falls in 2005, Canada, to develop and design the framework for a Reconciliation Movement in North America. As part of this process the groups' collective visioning has shaped the wisdom and perspectives that resulted in the Reconciliation in Child Welfare: Touchstones of Hope for Indigenous Children, Youth and Families document http://www. reconciliationmovement.org/docs/Touchstones of Hope.pdf.

\section{Bios}

Jean Lafrance has been involved in child welfare work for over 42 years, beginning as front line social work in northern Alberta in 1964 and serving in various leadership roles in northern, central and southern Alberta as well as in Edmonton and Calgary. He has also worked in staff development, policy and program development and strategic planning as an Assistant Deputy Minister, capping his 33 years in government as Alberta's Provincial Children's Advocate. He earned an MSW at Carleton
University in 1970 and a PhD in Social Work from the University of Southern California in 1993. He joined the Faculty of Social Work with the University of Calgary in 1997 where is now an Associate Professor with a keen interest in child welfare work with Aboriginal communities.

Betty Bastien works with the Access division at the Faculty of Social Work at the University of Calgary. She is Piikani and resides on the Blood Reserve, has taught and done curriculum design at Red Crow Community College in the Native Studies Department at the University of Lethbridge, and has conducted research on child development theories, child welfare, and Indigenous research methodologies. Betty was co-chair of the First Nations Adult and Higher Education Consortium Social Work Curriculum Development Task Force.

\section{References}

Bastien, B. (2004). Blackfoot ways of knowing: The worldview of the Siksikaitsitapi. Calgary, AB: University of Calgary Press.

Blackstock, C., Cross, T., George, J. Brown, I., and Formsma, J. (2005). Reconciliation in Child Welfare: Touchstones of Hope for Indigenous Children, Youth and Families document http://www. reconciliationmovement.org/docs/ Touchstones_of_Hope.pdf.

Bennett, M. \& Blackstock, C. (2002). Affirming and Promoting Indigenous Knowledge and Research, presentation, Winnipeg, MB: Centre of Excellence for Child Welfare, First Nations Child and Family Caring Society.

Blackstock, C. \& Trocmè. N. (2005). Community Based Child Welfare for Aboriginal Children; Supporting Resilience through Structural Change. In Ungar, M. (Ed.) Pathways to resilience: A Handbook of theory, methods and interventions. Thousand Oaks, CA: SAGE. 
Caldwell (1967). Indian Residential School Study. Prepared for Indian Affairs and Northern Development under the auspices of the Canada Welfare Council.

Carniol, B. (2005). In conversation with Anita Levin about the 5th edition of Case Critical: Social Justice and Social Services in Canada. http://www.btlbooks.com/Links/ carniol interview05.htm.

Elwell, Frank, 1996.The Sociology of Max Weber, Retrieved July 27, 2006 from http:// www.faculty.rsu.edu/ felwell/Theorists/ Weber/Whome.htm.

Hart, M.A. (1996). Sharing circles: Utilizing traditional practice methods for teaching, helping, and supporting. In S. O'Meara \& D.A. West (Eds.). From our eyes: Learning from Indigenous peoples (pp. 59-72). Toronto: Garamond Press.

Hart, M.A. (2002). Seeking Mino-pimatisiwin: An Aboriginal approach to healing. Halifax: Fernwood Publishing.

Henderson, J.Y. (2000). Context of the State of Nature. In Reclaiming Indigenous Voice and Vision. (Ed). Marie Battiste. UBC Press.

Johnson, P. (1983). Native Children and the Child Welfare System. Toronto: Canadian Council on Social Development.

Joint-Church Delegation of the Indian and Eskimo Residential School Commission: Indian Education - Suggestions for Improving the Prevailing System. (1930) (RG 10, volume 6730, file 169-62, pt. 2).

Lafrance, J. (2001) Paradox and Possibility in Child Protection Services. Unpublished Document

(c) Jean Lafrance and Betty Bastien
Little Bear, L. (2000). Jagged Worldviews Colliding. In Reclaiming Indigenous Voice and Vision. (Ed). Marie Battiste. UBC Press.

Marcel, G. (1949). Being and Having. Westminster: Dacre Press.

Morgan, G. (1986). Images of the Organization. Newbury Park: Sage Publications.

Morissette, V., McKenzie, B., \& Morrissette, L. (1993). Towards an Aboriginal model of social work practice: Cultural knowledge and traditional practices. Canadian Social Work Review, 10(1), 91-108.

Lise, N. (2000). Cited In Henderson, J.Y. The Context in the State of Nature. In Reclaiming Indigenous Voice and Vision. M. Battiste (Ed). Vancouver, BC: UBC Press.

Reconciliation: Looking Back, Reaching Forward. Indigenous People and Child Welfare, Retrieved from http://www. reconciliationmovement.org/activities/ october2005.html.

Richard, K. (2004) A Commentary against Aboriginal to non-Aboriginal adoption. First Peoples Child and Family Review: Journal on Innovation and Best Practices in Aboriginal Child Welfare Administration, Research, Policy and Practice, 1(1), 101109.

Ralston Saul, J.1995). Voltaire's Bastards: The dictatorship of reason in the west. Toronto: Viking.

Sahtouris, E. (1992). The survival path: Cooperation between indigenous and industrial humanity. Proceedings of the United Nations Policy Meeting on 
Indigenous Peoples. Santiago, Chile.

Retrieved from http://www.ratical.com/ LifeWeb/Articles/survival.html.

Taylor, F.W. (1922). Principles of scientific management. New York: Harper and Row.

Weber, Max. 1946/1958. From Max Weber. ranslated and edited by $\mathrm{H}$. H. Gerth and C. Wright Mills. New York: Galaxy.

Weber, M. (1904/1930). The Protestant Ethic and the Spirit of Capitalism. Translated by Talcott Parson. New York: Charles Scribner's Sons.

Weber, M. (1947). The Theory of Social and Economic Organization. London: Oxford University Press.

Zapf, M.K. (1992). Educating social work practitioners for the North: A challenge for conventional models and structures. The Northern Review, 7, 35-52. (Special theme issue on social work in the North).

Zapf, M.K. (1999a). Location and knowledgebuilding: Exploring the fit of western social work with traditional knowledge. Native Social Work Journal, 2(1), 139-153.

Zapf. M.K. (2003). Exploring the Spiritual Dimensions of Person and Place. Paper Presentation. Fantasyland Hotel. Edmonton, Alberta 